\title{
Fetal Neurohypophyseal Arginine Vasopressin and Arginine Vasotocin in Man and Sheep
}

\author{
W. RONALD SKOWSKY(2K) AND DELBERT A. FISHER \\ Departments of Endocrinology, Veterans Administration Hospital, Long Beach, and Harbor General Hospital, \\ Torrance, California, USA
}

\begin{abstract}
Summary
Immunoreactive arginine vasopressin (AVP) and arginine vasotocin (AVT) were quantitated in 15 of 17 human fetal pituitary glands early in gestation (11-19 weeks) and in 8 of 9 ovine fetal pituitary glands late in gestation (109-137 days). In 14 of 15 human fetal glands, AVT content exceeded that of AVP. There was a significant rise of $A V P$ (as a percentage of total AVP plus AVT content) with gestational age over the period of 12-19 weeks $(P<00.01)$. The ovine fetal glands demonstrated a preponderance of $A$ VP over $A$ VT. The mean AVP and AVT content in the ovine glands was $5.7 \pm 2.9$ and $0.8 \pm 0.2 \mathrm{mU} / \mathrm{mg}$ gland weight, respectively, compared with the values in the human fetal pitiutaries, $0.8 \pm 0.2$ and $1.2 \pm 0.2 \mathrm{mU} / \mathrm{mg}$ gland weight, respectively. The relative percentage of $A$ VP and $A V T$ in the ovine fetal pituitaries was $76.0 \pm 9.6 \%$ and $23.9 \pm 9.6 \%$, respectively, as contrasted to the human fetal glands, $36.7 \pm$ $2.7 \% \mathrm{AVP}$ and $63.3 \pm 2.7 \% \mathrm{AVT}$. The preponderance of AVT over AVP in the early gestational age mammalian fetus may represent a primative first step in molecular evolution of the neurohypophyseal peptides.
\end{abstract}

\section{Speculation}

The results suggest that fetal neurohypophyseal vasotocin, present in early fetal life, decreases with gestational maturation, with a corresponding increase in vasopressin. Further studies are needed in the same mammalian species periodically throughout gestation to confirm this chronologic change which suggests that ontogeny recapitulates phylogeny.

With the advent of sensitive radioimmunoassay (RIA) systems for peptide and steroid hormones, much information has been obtained regarding the hypothalamoneurohypophyseal physiology of the developing mammalian fetus. AVP has been quantitated within the fetal mammalian pituitary $(1,2,26)$ and kinetic studies have suggested autonomous fetal secretion at rates greatly exceeding maternal production (23). Recent reports have suggested the presence of the nonapeptide AVT in the fetal mammalian pituitary $(19,20,26)$ as well as in the mammalian pineal gland $(6,10,14,16)$. AVT also has been measured in the cerebral spinal fluid of adult mammals, including man $(7,15$, 17).

We have recently reported RIA systems for measurement of AVP (24) and AVT, using a differential antiserum protocol (21). The present study reports results applying this method to quantitation of AVP and AVT in early gestational age human fetal pituitary glands and late gestational age ovine fetal pituitary glands.

\section{MATERIALS AND METHODS}

All chemicals used were reagent grade except as indicated. Synthetic AVP (biopotency 300 units/mg) and synthetic AVT (biopotency 150 units/mg) were obtained from Schwarz/Mann Laboratories (27) and were used for standards and radioiodination.

\section{RADIOIMMIUNOASSAY PROCEDURES}

Antisera to AVP and AVT were produced in New Zealand White female rabbits, using lysine vasopressin conjugated to bovine thyroglobulin as previously described $(12,22)$. Synthetic AVP and AVT were iodinated, using a modification of the method of Hunter and Greenwood (24). Assay procedures were carried out as described earlier $(21,24)$, and bound and free hormones were separated exclusively by the double antibody method (13). All assays were carried out in duplicate, using both antiserum R-71 (specific for AVP) and antiserum R-70 (which measured both AVP plus AVT). AVT measurements are expressed as the difference between values measured with the two antisera. Using antiserum R-71, AVT showed negligible crossreactivity; the ratio of AVT:AVP at $50 \%$ binding was $350: 3$, and oxytocin (OXY) showed no significant cross-reaction with labeled antigen. Antiserum R-70 measured AVP and AVT with similar cross-reactivity while OXY showed a somewhat parallel response with cross-reactivity demonstrated at concentrations of OXY:AVT greater than $5: 1$. The coefficient of variation (CV) for measurement of AVP (using R-71) was $7.1 \%$ within assay and $14.9 \%$ between assay. Using $R-70$, the within assay $C V$ was $8.8 \%$ whereas between assay $\mathrm{CV}$ was $12.9 \%$.

\section{PROCESSING OF TISSUE SAMPLES}

Human fetal pituitaries (11-19 weeks of gestation) were obtained following induced therapeutic abortion via dilatation and curettage or, in a few instances, saline lavage. No significant or unusual maternal drug medication nor maternal illness was documented. Gestational age of the fetus was confirmed by crownrump measurement after the standards of Streeter (25). The pituitary gland was manually dissected from surrounding tissue within $10 \mathrm{~min}$ of fetal evacuation, immediately weighed, dried in acetone for $18 \mathrm{hr}$, and then dehydrated in vacuo. Each gland was pulverized and homogenized in $1.0 \mathrm{ml}$ phosphate $(50 \mathrm{M})$ buffered saline $(154 \mathrm{mM}, \mathrm{pH} 7.5)$ at $4^{\circ}$ in a small glass homogenizer. The homogenates were stored at $-20^{\circ}$ until thawed and diluted in buffer for RIA measurement.

Normal fetal sheep pituitaries were obtained at 109-137 days of gestation, following surgical uterotomy under spinal anesthesia in 1-4-year-old Columbia or Columbia-Suffolk ewes datebred to Columbia or Suffolk rams obtained from a local source. Gestational age of the fetus was again confirmed by crown-rump measurement. The tissue was obtained within $10 \mathrm{~min}$ after delivery, weighed, processed, and stored as described above until RIA measurement.

\section{RESULTS}

Table 1 lists the immunologic AVP and AVT activity in the human and sheep fetal pituitaries; values are expressed both as a 
Table 1. Arginine vasopressin (AVP) and vasotocin (AVT) content in fetal human and sheep pituitary glands in milliunits of $A V P$ and $A V T$ per mg gland weight, percentage of $A V P$ and $A V T$, and $A V P: A V T$ ratios'

\begin{tabular}{|c|c|c|c|c|c|}
\hline \multirow[b]{2}{*}{ Age, weeks } & \multicolumn{2}{|c|}{$\mathrm{mU} / \mathrm{mg}$ wet wt } & \multicolumn{3}{|c|}{$\%$} \\
\hline & A VP & AVT & AVP & AVT & $\begin{array}{l}\text { AVP: } \\
\text { AVT }\end{array}$ \\
\hline \multicolumn{6}{|c|}{ lluman fetal pituitary glands } \\
\hline 11 & N.D. & N.D. & & & \\
\hline 12 & 0.6 & 1.6 & 27.9 & 72.1 & 0.39 \\
\hline 12 & 0.3 & 1.1 & 21.1 & 78.9 & 0.26 \\
\hline 13 & 0.6 & 1.3 & 30.9 & 69.1 & 0.45 \\
\hline 13 & N.D. & N.D. & & & \\
\hline 14 & 0.1 & 0.3 & 27.8 & 72.2 & 0.39 \\
\hline 14 & 0.2 & 0.5 & 29.8 & 70.2 & 0.43 \\
\hline 15 & 0.6 & 1.1 & 36.1 & 63.9 & 0.57 \\
\hline 15 & 0.1 & 0.5 & 17.7 & 82.3 & 0.22 \\
\hline 16 & 1.6 & 2.9 & 35.6 & 64.4 & 0.55 \\
\hline 16 & 0.1 & 0.1 & 45.4 & 54.6 & 0.83 \\
\hline 17 & 0.7 & 0.9 & 42.4 & 57.6 & 0.74 \\
\hline 17 & 2.2 & 2.0 & 52.0 & 48.0 & 1.08 \\
\hline 18 & 1.8 & 2.1 & 46.0 & 54.0 & 0.85 \\
\hline 18 & 2.8 & 2.8 & 49.6 & 50.4 & 0.98 \\
\hline 19 & 0.8 & 0.9 & 45.2 & 54.8 & 0.82 \\
\hline 19 & 0.1 & 0.1 & 43.5 & 56.5 & 0.77 \\
\hline Mean & 0.8 & 1.2 & 36.7 & 63.3 & 0.62 \\
\hline SEM & 0.2 & 0.2 & 2.7 & 2.7 & 0.01 \\
\hline \multicolumn{6}{|c|}{ Ovine fetal pituitary glands } \\
\hline 109 & N.D. & N.D. & & & \\
\hline 120 & 3.6 & 0.9 & 79.8 & 20.2 & 3.96 \\
\hline 120 & 2.9 & 0.3 & 89.5 & 10.5 & 8.53 \\
\hline 124 & 5.0 & 0.1 & 98.6 & 1.4 & 68.49 \\
\hline 129 & 4.2 & 0.3 & 94.2 & 5.8 & 16.24 \\
\hline 135 & 3.4 & 0.5 & 87.2 & 12.8 & 6.80 \\
\hline 135 & 0.4 & 0.5 & 42.6 & 57.4 & 0.74 \\
\hline 137 & 25.4 & 2.4 & 91.4 & 8.6 & 10.62 \\
\hline 137 & 0.4 & 1.2 & 25.0 & 75.0 & 0.33 \\
\hline Mean & 5.7 & 0.8 & 76.0 & 23.9 & 14.46 \\
\hline SEM & 2.9 & 0.2 & 9.6 & 9.6 & 7.93 \\
\hline
\end{tabular}

1 ND: nondetectable.

percentage of total AVP and AVT content and as a relative ratio of AVP:AVT. In the human fetal pituitaries examined, AVP and AVT were measureable in 15 of 17 glands. Neither hormone was detectable in two human glands (11 and 13 weeks of gestation). Inability to measure AVP and AVT in the current study indicates tissue levels less than $10 \mu \mathrm{U} / \mathrm{mg}$ wet weight of pituitary. It is also possible that the gestational age estimation was incorrect and misleading or that the neurohypophysis was not included in the tissue removed from the fetal sella turcica at the time of therapeutic abortion. It is unlikely that immunologic inactivation of the peptides occurred during prolonged storage of the pituitary tissue, as we have previously demonstrated immunologic stability for at least 6 months under similar conditions (24).

The absolute quantity of immunoreactive AVP and AVT in the human fetal pituitaries throughout 12-19 weeks of gestation is graphically illustrated in Figure 1. In all tissues except one (17 weeks of gestation) in which both peptides were present in measureable amounts, AVT content exceeded that of AVP. Although there is a suggestion that the absolute amount of AVP appears to increase through 19 weeks, this correlation is not statistically significant. However, when the data is presented as immunoreactive AVP as a percentage of total AVP plus AVT content, there is a highly significant correlation between a rising percentage of AVP and gestational age over the period of 12-19 wecks (correlation coefficient $=0.801 . P<0.01$ ); this is illustrated in Figure 2. Conversely, the perentage of $A V T$ demonstrates a statistically significant decrease over the similar time period in the human fetal pituitaries.

The values for immunoreactive AVT obtained in the present study are subject to a possible error in interpretation. As we have previously reported, our differential radioimmunoassay procedure demonstrates a cross-reactivity of OXY when combined AVP-AVT content is measured. Antiserum R-70 shows a displacement of tracer-labeled antigen by OXY when the ratio of OXY:AVT is greater than 5:1. The present series of studies did not incorporate an initial chromatographic separation of $\mathrm{OXY}$ and, if OXY was present in large amounts in the tissue extracts, this would have produced falsely elevated immunoreactive AVT measurements. Presently, there is no evidence to suggest the presence of $O X Y$ in the human fetal neurohypophysis at this gestational time period. Moreover, it is improbable that, if synthesized OXY is stored within the tissue, it would be present

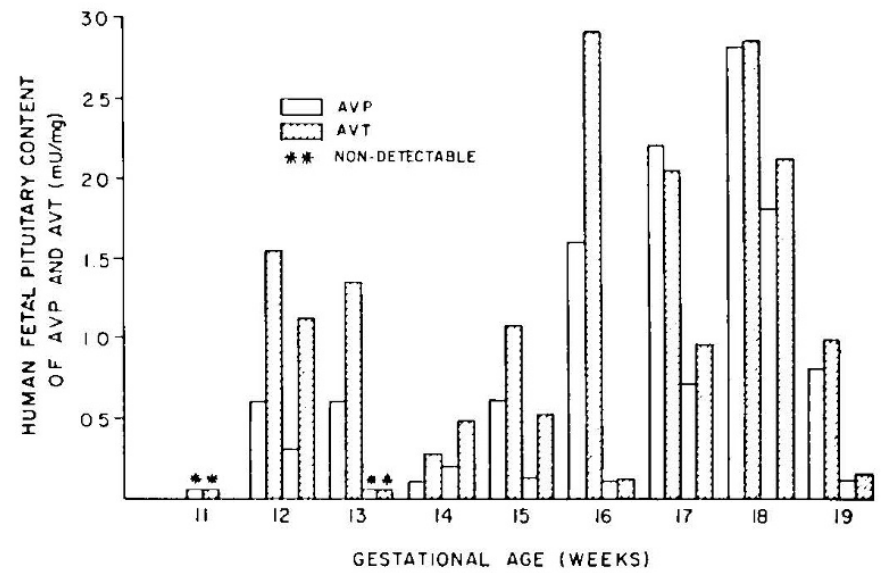

Fig. 1. Immunoreactive AVP and AVT in the human fetal pituitary glands of 11-19 weeks of gestation. Results are expressed as milliunits of hormone per mg gland weight. Neither hormone was measurable in the 11 -week gestational age gland nor in one of the 13-week gestational age glands.

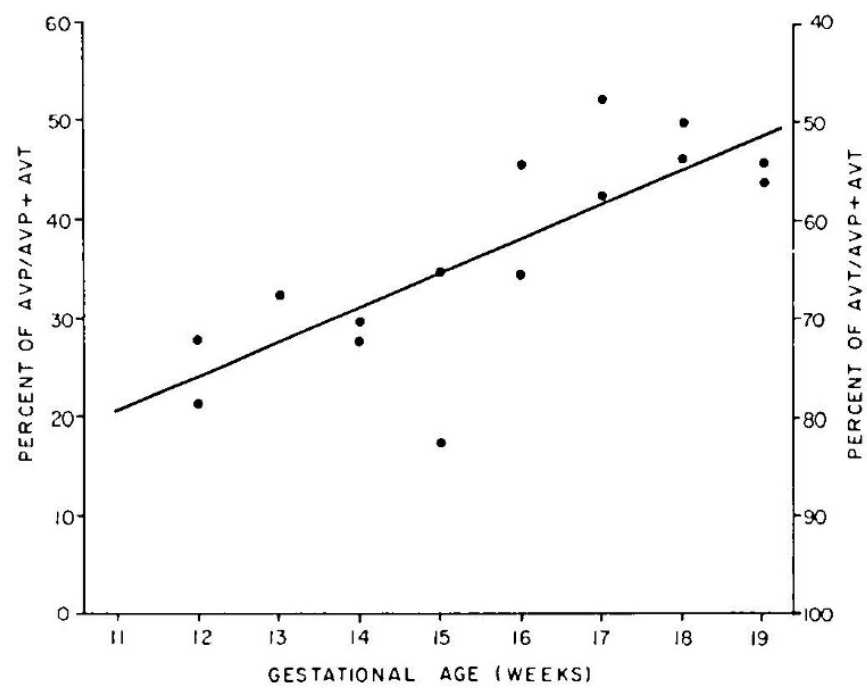

Fig. 2. Correlation of immunoreactive $A V P$ and $A V T$ as a percentage of total AVP plus AVT content versus gestational age in weeks in the human fetal pituitary glands. The results show a correlation coefficient of $0.801(P<0.01)$ over the gestational time period of $12-19$ weeks. 
in quantitics that exceed that of AVT by greater than $5: 1$. The immunoreactive amounts of AVP reported are not subject to this possible error, as the antiserum used to quantitate AVP (R71) does not demonstrate cross-reactivity to OXY.

The immunologic AVP and AVT activity in the late gestational age sheep fetal pituitaries is tabulated in the lower portion of Table 1. Both AVP and AVT were measureable in eight of nine glands examined. Neither peptide hormone could be detected in the 109-day ovine fetus, the earliest gestational date studied.

The 120-137-day ovine fetal pituitaries demonstrated a preponderance of AVP over AVT content in six of eight glands examined. It is unclear why two late gestational age fetal glands (135 and 137 days) showed a larger pereentage of AVT. Both of these pituitaries had the smallest actual quantity of immunologic AVP of all the ovine tissue studied $(0.4 \mathrm{mU} / \mathrm{mg}$ wet weight $)$, much less than would be predicted from similar gestational-aged glands.

Since the ovine pituitaries were obtained from sheep at $120-$ 137 days of gestation, which represents the final 2 weeks of pregnancy (term 145 days), no attempt was made at chronologic analysis. The mean AVP and AVT content in the eight ovine fetal glands was $5.7 \pm 2.9$ and $0.8 \pm 0.2 \mathrm{mU} / \mathrm{mg}$ gland weight. respectively, as compared with the values in the human fetal pituitaries, $0.8 \pm 0.2$ and $1.2 \pm 0.2 \mathrm{mU} / \mathrm{mg}$ gland weight. respectively. The relative percentage of $A V P$ and $A V T$ content in the eight ovine fetal pituitaries was $76.0 \pm 9.6 \%$ and $23.9 \pm$ $9.6 \%$, respectively, as constrated to the human fetal glands, $36.7 \pm 2.7 \%$ AVP and $63.3 \pm 2.7 \%$ AVT.

The data suggest a relative preponderance of AVT over AVP early in mammalian fetal development (as demonstrated in the human fetal pituitaries) with an absolute decrease in AVT and concomitant rise in AVP content late in fetal life (as seen in the ovine fetal pituitaries). The relative amounts of AVP and AVT in early and late gestation can be quantified by expressing the values as an AVP/AVT ratio (Fig. 3). An AVP/AVT ratio $<1.0$ indicates a quantity of AVP less than AVT and an AVP/AVT ratio $>1.0$ suggests a quantity of AVP greater than $A V T$. The ratios obtained from 14 of 15 human fetal glands with immunologically measureable hormones are less than 1.0 with a rise in the ratio with advancing fetal age. This chronologic increase in the AVP:AVT ratio represents both an actual increase in the percentage of AVP content as well as a measureable decrease in percent AVT content. The mean AVP:AVT ratio of all the human fetal glands is $0.62 \pm 0.01$.

The ovine fetal pituitaries demonstrate an AVP:AVT ratio $>1.0$ in six of eight glands examined, representing. for the most part, an absolute percentage increase in AVP. The mean AVP:AVT ratio in the fetal sheep glands is $14.46 \pm 7.93$.

It is probable that the OXY content of the ovine fetal pituitary glands is elevated at this late gestational time period and the AVP:OXY ratio has been reported to be about 5 in fetal sheep $(20,26)$. Some percentage of the immunoreactive AVT may, indeed, represent OXY cross-reactivity. However, the AVP values measureable (by $\mathrm{R}-71$ antisera) do not represent RIA displacement by elevated OXY levels and suggest valid interpretations. Moreover, as AVP:AVT ratios never rose above 120:1, it is unlikely that small quantities of $A V T$ were obscured by large amounts of AVP. Thus, the observation in the ovine fetal pituitaries that the AVP:AVT ratios are relatively high late in gestation appears to be valid.

\section{DISCUSSION}

We have utilized a recently developed differential RIA system for quantitiating immunoreactive AVP and AVT in the early gestational age human fetal neurohypophysis and in the late gestational age ovine fetal neurohypophysis. The results suggest that early in human fetal development, the posterior pituitary gland contains a preponderance of stored arginine vasotocin

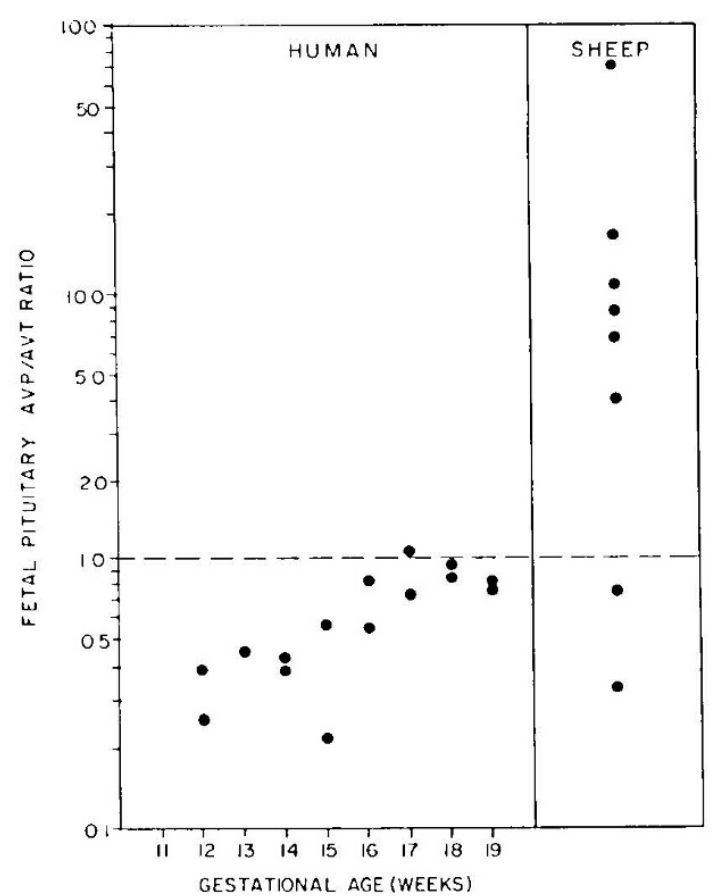

Fig. 3. Fetal pituitary AVP:AVT ratios in the human and ovine glands. A ratio $<1.0$ indicates a preponderance of $A V T$ and a ratio $>1.0$ indicates greater AVP. The ratio in 14 of 15 human fetal glands is $<1.0$ and the ratio in 6 of 8 of the ovine glands is $>1.0$.

relative to arginine vasopressin and that this peptide ratio decreases over the chronologic time period of 12-19 weeks. In the near term mammalian ovine fetal pituitary gland, arginine vasopressin is the predominant vasopressor peptide present with only small amounts of arginine vasotocin. However, as these data reflect studies in two different mammalian species, it would be presumptuous to regard the results as representing a continuity of neurohypophyseal development throughout mammalian gestation.

The presence of arginine vasopressin in the fetal mammalian pituitary gland has been documented by other investigators ( 1 , $2,22,26)$. Recently, Burton and Forsling (2) detected AVP immunoreactivity in the fetal guinea pig neurohypophysis after 20 days of gestation (term $=64$ days). There was an increase in pituitary content with increasing age. Perks and Vizsolyi (20) demonstrated bioassayable AVP in the fetal pituitaries of sheep and seals at midgestation.

Recent reports have suggested the presence of AVT within the fetal pituitary gland as well as in the fetal pineal gland. Bioassayable AVT has been identified chromatographically shortly after midterm in the neurohypophysis of the fetal seal, sheep, and guinea pig $(20,26)$. These investigators, however, reported biologic activities for AVT and AVP in the term fetal ovine neurohypophysis which were 10 times greater than our results. In addition, Pavel (19) has reported biologic activities for AVT and AVP in 20-22-week human fetal glands over 50-fold higher than our data suggests. It is uncertain why this discrepancy exists. Although the above studies utilized an acetic acid extraction (rather than our method of acetone drying), we have been unable to demonstrate any differences in immunologic activity of AVP or AVT with either method (unpublished observations). It is possible that both methods may alter immunoreactivity with minor effects on biologic activity. The possibility exists, however small, of a prohormone or neurophysin-peptide complex that is not recognized by our antisera yet still possesses activity under the conditions of the bioassay. This might also account for the ability of Pavel (19) to detect biologically active AVT (albeit no AVP) in human fetal neurohypophysis of 8-9 weeks of gesta- 
tion-an earlier gestational time for the presence of AVT than our studies would suggest. If the reason for discrepancy of absolute values of $A V P$ and $A V T$ between other laboratories and ours is due to a constant factor, then the ratios of peptides could still be valid.

Pavel has demonstrated the ability to synthesize a vasotocinlike peptide in vitro of fetal human pineal tissue of 95-115 days of gestation (19) (and as early as 55-65 days). These studies suggest that the fetal neurohypophysis functions as a neurosecretory organ as well as a storage site for AVT. The presence of ependymal cells in the mammalian fetal posterior pituitary that are morphologically similar to those in the fetal pineal gland may represent the site of synthesis of AVT. The fetal neurohypophyscal ependymal cells (but not those in the pineal) disappear after birth, correlating with the disappearance of AVT from the posterior pituitary gland of the adult mammal.

The values for immunoreactive AVT in the present study are valid only if OXY is present in ratios less than $4: 1$. Studies in the fetal guinea pig suggest undetectable levels of OXY until after 46 days (term $=64$ days) (2). Data from fetal sheep, seals and pigs suggest extremely low OXY levels till well after midterm. Indeed, even at parturition, the OXY content of the fetal neurohypophysis is far below adult levels: $7-10 \%$ of adult values in the guinea pig (2), 30\% in the pig, $35 \%$ in the seal, and $8 \%$ in the sheep $(20,26)$. Indeed, there is evidence that the increased levels of OXY in fetal blood at parturition in the goat $(4,9)$, man (5), and guinea pig (3) reflect, to a major degree, placental transport of maternal OXY. It therefore seems unlikely that significant elevation of fetal neurohypophyseal OXY accounted for the elevated values of AVT in the 12-19-sveek human fetal glands. Although the OXY contained in the term fetal slecep glands (albeit in smaller amounts than in adult glands) may be sufficient to cross-react with immunoassayable AVT, the elevated AVP:AVT ratio would still be valid.

The physiologic role of AVT in the early gestational age mammalian fetus is uncertain at the present time. It may represent a primitive first step in molecular evolution of the neurohypophyseal peptides. In lower vertebrates, AVT has biologic activity on the cardiovascular and reproductive systems (11), as well as upon renal and extrarenal fluid and electrolyte regulation (8). Preliminary observations by Perks and Vizsolyi (20) suggest a role in regulation of water movement across embryonic membranes. Hydrostatic and osmotic water flow across placental amniotic and allantoic membranes is slowed or reversed in the presence of vasotocin. Conceivably, fetal production of AVT may produce changes of a beneficial nature in the fluid homeostatic milicu. This function may be passed on to AVP with ensuing ontogenetic development of the fetal brain.

\section{CONCLUSION}

Immunoreactive arginine vasopressin and arginine vasotocin have been quantitated in early gestational age human fetal pituitary glands (11-19 weeks) and late gestational age ovine fetal pituitary glands (109-137 days) using a recently developed differential radioimmunoassay system. The human glands contained more vasotocin $(1.2 \pm 0.2 \mathrm{mU} / \mathrm{mg}$ gland) than vasopres$\sin (0.8 \pm 0.2 \mathrm{mU} / \mathrm{mg}$ gland $)$ with a mean vasopressin to vasotocin ratio of $0.62 \pm 0.01$. The absolute quantity of vasotocin decreased and that of vasopressin increased through the period of 11-19 weeks. The ovine glands contained more vasopressin $(5.9 \pm 2.9 \mathrm{mU} / \mathrm{mg}$ gland $)$ than vasotocin $(0.8 \pm 0.2 \mathrm{mU} / \mathrm{mg}$ gland) with a mean vasopressin to vasotocin ratio of $14.4 \pm$ 7.93 .

\section{REFERENCES AND NOTES}

1. Alexander, D. P., Britton, H. G., Forsling, M. L., Nixon, D. A., and Radcliff, J. G.: The release of corticotrophin and vasopressin in the foetal sheep in response to haenioninage. J. Physiol., 213: $31 \mathrm{P}$ (1971).

2. Burton, A. M., and Forsling, M. L.: Hormone content of the neurohypophysis in foetal, new-born and adult guinea-pigs. J. Physiol., 221: 6P (1972).

3. Burton, A. M., Illingworth, D. V., Challis, J. R. G., and Miceilly, A. S.: Placental transfer of oxytocin in the guinea pig and its release during parturition. J. Endocrinol., 60: 499 (1974).

4. Chard, T., Boyd, N. R. H., Forsling, M. I., McNeilly, A. S., and Landon, J.: The development of a radioimmunoassay for oxytocin: The extraction of oxytocin from plasma, and its measurement during parturition in human and goat blood. J. Endocrinol., 48: 223 (1970).

5. Chard, T., Hudson, C. N., Edwards, C. R. W., and Boyd, N. R. H.: Release of oxytocin and vasopressin of the human foetus during labour. Nature, 234: 352 (1971)

6. Chessman, D. W.: Structural elucidation of a gonadotropin-inhibiting substance from the bovine pineal gland. Biochim. Biophys. Acta, 207: 247 (1970).

7. Coculescu, M., and Pavel, S.: Arginine vasotocin-like activity of cerebrospinal fluid. J. Clin. Endocrinol. Metab., 31: 369 (1970)

8. Henderson, I. W., and Wales, N. A. M.: Renal diuresis and antidiuresis after injections of arginine vasotocin in the fresh water eel. J. Endocrinol., 61: 487 (1974).

9. McNeilly, A. S., Martin, M. J., Chard, T., and Hart, I.: Simultancous release of oxytocin and neurophysin during parturition in the goat. J. Endocrinol., 52: 213 (1972).

10. Mileau, S. M., Pavel, S., and Neacsu, C.: Biological and chromatographic characterization of a polypeptide with pressor and oxytocic activities isolated from bovine pineal gland. Endocrinology, 72: 563 (1963).

11. Morel, E., and Jard, S.: Actions and functions of the neurohypophysial hormones and related peptides in lower vertebrates. In: Neurohypophysial hormones and similar poly-peptides. Handbuch der Experimentellen Pharmakologie, Vol. 23, p. 653 (Springer-Verlag, Berlin, 1965).

12. Odell, W. D., Skowsky, W. R., Abraham, G., Hescox, M., Fisher, D., and Grover, P. K.: Production of antisera for polypeptide and steroid radioimmunoassay, Biol. Reprod., 6: 427 (1972).

13. Odell, W. D., Rayford, P. L., and Ross, G. 1.: Simplified, partially auto mated method for radioimmunoassay of human thyroid-stimulating, growth luteinizing, and follicle stimulating hormones. J. Lab. Clin. Med., 70: 973 (1967).

14. Pavel, S.: Evidence for the presence of lysine vasotocin in the pig pineal gland. Endocrinology, 77: 812 (1965).

15. Pavel, $S$.: Tentative identification of arginine vasotocin in human cerebrospinal fluid. J. Clin. Endocrinol. Metab., 31: 369 (1970).

16. Pavel, S.: Evidence for the epenoymal origin of arginine vasotocin in the bovine pineal gland. Endocrinology, 89: 613 (1971).

17. Pavel, S., and Coculescu, S.: Arginine vasotocin-like activity of cerebrospinal fluid induced by injection of hypertonic saline into the third cerebral ventricle of cats. Endocrinology, 91: 825 (1972).

18. Pavel, S., Dorcescu, M., Petrescu-Holban, R., and Ghinea, E.: Biosynthesis of a vasotocin-like peptide in cell cultures from pineal glands of human fetuses. Science, 181: 1252 (1973).

19. Pavel, S.: Vasotocin biosynthesis by neurohypophysial cells from human fetuses. Evidence for its ependymal origin. Neuroendocrinology, 19: 150 (1975).

20. Perks, A. M., and Vizsolyi, E.: Studies of the neurohypophysis in foetal animals. In: Foetal and Neonatal Physiology, Proceedings of the Sir Joseph Barcroft Centenary Symposium, p. 430 (Cambridge University Press, Cambridge, England, 1973).

21. Rosenbloom, A. A., and Fisher, D. A.: Radioimmunoassay of arginine vasotocin, Endocrinology, 95: 1726 (1974).

22. Skowsky, W. R., and Fisher, D. A.: The use of thyroglobulin to induce antigenicity to small molecules, J. Lab. Clin. Med., 80: 134 (1972).

23. Skowsky, W. R., Bashore, R. A., Smith, F. G., and Fisher, D. A.: Vasopressin metabolism in the foetus and newborn. In: Foetal and Neonatal Physiology, Proceedings of the Sir Joseph Barcroft Centenary Symposium, p. 439 (Cambridge University Press, Cambridge, England, 1973).

24. Skowsky, W. R., Rosenbloom, A. A., and Fisher, D. A.: Radioimmunoassay measurement of arginine vasopressin in serum: Development and application. J. Clin. Endocrinol. Metab., 38: 278 (1974).

25. Streeter, G. L.: Weight, sitting, head size, foot length, and menstrual age of the human embryo. Embryology, 11(55): 143 (1920).

26. Vizsolyi, E., and Perks, A. M.: New neurohypophysial principal in foetal animals. Nature, 233: 1169 (1969).

27. Orangeburg, New York.

28. Requests for reprints should be addressed to: W. R. Skowsky, M.D., Department of Endocrinology, Long Beach Veterans Hospital, 5901 E. 7th St., Long Beach, Calif. 90822 (USA).

29. Received for publication June $18,1976$.

30. Accepted for publication September $15,1976$. 